\title{
POTENSI EKOWISATA BERBASIS MASYARAKAT KAMPUNG URUG, SUKAJAYA, BOGOR
}

\section{(Community-Based Ecotourism Potential in The Urug Villages, Sukajaya, Bogor)}

\author{
MENTARI AURELIA ${ }^{1 *}$, NANDI KOSMARYANDI ${ }^{2)}$ DAN SITI AMANAH ${ }^{3)}$ \\ 1) Program Studi Magister Manajemen Ekowisata dan Jasa Lingkungan, Sekolah Pasca Sarjana Institut Pertanian \\ Bogor, Kampus Darmaga, Bogor, Indonesia 16680 \\ 2) Departemen Konservasi Sumberdaya Hutan \& Ekowisata, Fakultas Kehutanan Institut Pertanian Bogor, Kampus \\ Darmaga, Bogor, Indonesia 16680 \\ 3) Departemen Sains Komunikasi dan Pengembangan Masyarakat, Fakultas Ekonomi dan Manajemen Institut \\ Pertanian Bogor, Kampus Darmaga, Bogor, Indonesia 16680
}

*Email: mentariaurelia@gmail.com

Diterima 18 September 2019 / Disetujui 26 Desember 2019

\begin{abstract}
Rural communities have a tendency to find other work outside agricultural sector. This happens because of industrial employment is way more attractive in urban areas than in rural areas that is related to economic aspects. However, this alteration did not affect Kampung Urug (Urug Village). This is due to the three principles of local wisdom that the village had namely titipan (protection function), tutupan (maintenance function), and awisan (cultivation function). This village has ecological potential including natural and environmental resources that can be used as ecotourism assets beside socio-culture potential. This study analyzesd the ecological potential and formulates the strategies in community-based ecotourism management using observational methods to retrieve ecological potential data, and survey methods through questionnaires and interviews with respondents for the SWOT analysis approach so as to formulate community-based ecotourism management. Some ecological potentials that can be considered in Urug Village are (1) plant diversity commonly used by the community, (2) primate species such as Javan langur (Trachypithecus auratus) and long-tailed monkeys (Macaca fascicularis) and birds such as Javan eagle (Nisaetus bartelsi), srigunting (Dicrurus macrocercus), and Javanese Kingfisher (Halcyon cyanoventris), and (3) rice fields and rivers. Meanwhile the socio-cultural aspects of the community both in traditional ceremonies and traditional institutions. Based on the SWOT analysis, the management strategy is in accordance with quadrant I (1.31-1.78), that is an aggressive strategy based on the influence of internal and external factors.
\end{abstract}

Keywords: ecological potential, ecotourism, local wisdom, Urug village

\section{ABSTRAK}

Masyarakat pedesaan memiliki kecenderungan untuk mencari pekerjaan lain di luar pertanian. Hal ini terjadi karena lapangan kerja industri lebih menarik dalam perkotaan daripada pedesaan yang terkait dengan aspek ekonomi. Perubahan tersebut tidak mempengaruhi Kampung Urug karena tiga prinsip kearifan lokal yang dimiliki kampung ini, yaitu titipan (fungsi perlindungan), tutupan (fungsi pemeliharaan), dan awisan (fungsi budidaya). Tidak hanya potensi pertanian, kampung ini memiliki potensi ekologi termasuk sumber daya alam dan lingkungan yang dapat digunakan sebagai aset ekowisata. Penelitian ini menganalisis potensi ekologi dan merumuskan strategi dalam pengelolaan ekowisata berbasis masyarakat menggunakan metode observasi untuk mengambil data potensi ekologi, dan metode survei melalui kuesioner dan wawancara kepada responden untuk pendekatan analisis SWOT sehingga dapat merumuskan pengelolaan ekowisata berbasis masyarakat.Beberapa potensi ekologis yang dapat dipertimbangkan di Kampung Urug adalah (1) keanekaragaman tanaman yang biasa digunakan oleh masyarakat, (2) spesies primata seperti lutung jawa (Trachypithecus auratus) dan monyet ekor panjang (Macaca fascicularis) dan burung seperti elang jawa (Nisaetus bartelsi), srigunting (Dicrurus macrocercus), dan cakakak jawa (Halcyon cyanoventris), dan (3) sawah dan sungai. Sementara itu sosial budaya masyarakat baik dalam upacara adat maupun kelembagaan adat. Berdasarkan analisis SWOT, strategi pengelolaan sesuai dengan kuadran I (1,31-1,78) yaitu strategi agresif berdasarkan pengaruh faktor internal dan eksternal.

Kata kunci: ekowisata, Kampung Urug, kearifan lokal, potensi ekologi

\section{PENDAHULUAN}

Kegiatan pariwisata berkembang pesat karena didukung oleh kekayaan alam, keanekaragaman hayati flora dan fauna, peninggalan sejarah serta keanekaragaman budaya, dan ritual keagamaan. Perkembangan pariwisata yang banyak diminati adalah objek wisata alam, hal ini dapat memberikan dampak yang positif seperti meningkatkan pertumbuhan ekonomi namun juga dapat menimbulkan dampak negatif seperti terjadinya degradasi lingkungan alam, sosial dan budaya tempat tujuan wisata (John dan Vijayan 2018). Peningkatan kesadaran terhadap lingkungan secara global berakibat pada perubahan parisawata yang mulanya ekslporatif menjadi berkelanjutan yang biasa disebut ekowisata (Widada 2008). Sekartjakrarini (2004) menyatakan, bahwa konsep ekowisata merupakan konsep pengembangan dan penyelenggaraan kegiatan pariwisata 
berbasis pemanfaatan lingkungan untuk perlindungan serta melibatkan partisipasi aktif masyarakat dengan penyajian produk bermuatan pendidikan dan pembelajaran, memiliki dampak negatif terhadap lingkungan yang minim, memberikan kontribusi positif terhadap pembangunan daerah dan dilaksanakan pada kawasan lindung, kawasan terbuka, kawasan binaan, serta kawasan budaya. Ekowisata bukan hanya program wisata yang yang memanfaatkan potensi alam dan budaya tetapi juga memanfaatkan dukungan masyarakat lokal dalam menjalankan program-program kegiatan ekowisata sehingga disebut sebagai ekowisata berbasis masyarakat. Pola ekowisata berbasis masyarakat adalah pola pengembangan ekowisata yang mendukung dan memungkinkan keterlibatan penuh oleh masyarakat setempat dalam perencanaan, pelaksanaan, dan pengelolaan usaha ekowisata dan segala keuntungan yang diperoleh (WWF Indonesia 2009).

Budaya masyarakat yang dimiliki di Indonesia merupakan masyarakat agraris namun semakin perlahan masyarakat akan menjadi individu yang modern dan dinamis, seperti halnya pada aspek kehidupan sehari-hari di kota-kota besar dengan pola nilai-nilai perilaku yang telah berubah (Prasetyadi et al. 2005). Tetapi tidak semua daerah memiliki kecepatan perubahan yang sama dalam memandang perkembangan dunia, salah satunya adalah Kampung Urug. Hal ini didasari oleh tiga prinsip kearifan lokal yaitu titipan (fungsi perlindungan), tutupan (fungsi pemeliharaan), dan awisan (fungsi budidaya) sehingga mereka tetap diwajibkan menanam padi secara berkala sesuai peraturan yang diberikan oleh ketua adat. Kampung Urug berada di Desa Urug, Kecamatan Sukajaya, yang berada di bagian Bogor Barat. Prasetyadi et al. (2005) menyatakan bahwa hasil pendapatan masyarakat Kampung Urug umumnya diperoleh dari bercocok tanam dan bertani, hal ini disebabkan karena pola perkampungan padat dan tersebar di muara sungai. Daya tarik wisata yang dimiliki kampung ini adalah peninggalan sejarah seperti arsitektur bangunan dan upacara adat yang di selenggarakan setiap lima kali setahun (Ruwahan, Sereun Taun, 1 Muharram, Maulied, dan Sedekah Bumi), serta masyarakat di kampung ini juga memiliki kerja sama yang baik, dapat dilihat ketika akan menyelenggarakan upacara adat tersebut (Dewantara 2013). Daya tarik tersebut telah di legalitaskan oleh Dinas Pariwisata Kabupaten Bogor sebagai cagar budaya pada tahun 2012. Kampung Urug juga memiliki potensi ekologis yang dapat menjadi wisata lain yaitu seperti keanekaragaman hayati flora dan fauna, dan bentang alam, dan Hutan Larangan yang tidak boleh dimanfaatkan oleh masyarakat Urug. Salah satu jenis tanaman yang terdapat di kampung ini adalah jenis yang di manfaatkan oleh masyarakat sebagai bahan bangunan rumah adat dan jenis faunanya merupakan satwa primata yang biasa dijumpai di sawah masyarakat di Kampung Urug.

Potensi-potensi tersebut yang akan menjadi nilai tambah dalam pengembangan ekowisata di Kampung Urug. Akan tetapi Kampung Urug belum memiliki data jenis flora dan fauna, serta belum adanya pengelolaan yang diterapkan dalam kegiatan ekowisata dengan tujuan menjaga kelestarian lingkungan. Berdasarkan hal tersebut, maka tujuan penelitian ini adalah mengindentifikasi dan mendeskripsikan jenis-jenis potensi ekologis dan sosial budaya masyarakat serta menemukan pengelolaan ekowisata berbasis masyarakat yang dapat memberikan manfaat secara sosial, dan lingkungan di Kampung Urug.

\section{METODE PENELITIAN}

Penelitian dilakukan pada bulan Desember 2018 hingga Januari 2019. Lokasi penelitian berada di Kampung Urug, Desa Urug, Kecamatan Sukajaya, Kabupaten Bogor yang dapat dilihat pada Gambar 1. Lokasi ini dipilih karena (a) Lokasi ini merupakan salah satu pusat wisata budaya atau dikenal dengan kampung adat yang telah berjalan di Kabupaten Bogor, (b) masyarakat kampung ini memiliki sifat yang ramah dan terbuka terhadap pengunjung atau tamu, dan (c) terdapat potensi alam berupa keanekaragaman flora dan fauna.

Metode yang digunakan adalah survei lapangan berupa eksplorasi, kuesioner serta wawancara. Pengambilan sampel untuk (1) Potensi ekologis dengan menggunakan metode jelajah yang dilaksanakan selama tujuh hari dengan tiga lokasi yang berbeda yaitu lokasi pertama berada di wilayah Sungai Cidurian, lokasi kedua berada di kawasan Gunung Leutik dan Gunung Mani'is, dan ketiga berada di wilayah sekitar perbatas Desa Kiarasari dengan pengamatan yang dilakukan dua kali pada pagi hari (06.00-11.00 WIB) dan siang hari (13.0017.00 WIB) untuk mendapatkan jenis-jenis flora dan fauna (Alikodra 2000). (2) Potensi sosial budaya masyarakat Urug dengan menggunakan studi literatur dengan mengumpulkan data-data sekunder (Prasetyadi et al. 2005; Dewantara 2013; Yogasari 2018), serta melalui kuesioner dan wawancara dari sumber yang terkait dengan penelitian. (3) Analisis SWOT dilakukan dengan pengambilan responden melalui informan kunci yang merupakan tokoh-tokoh penting dalam keterlibatan setiap kegiatan di Kampung Urug. 


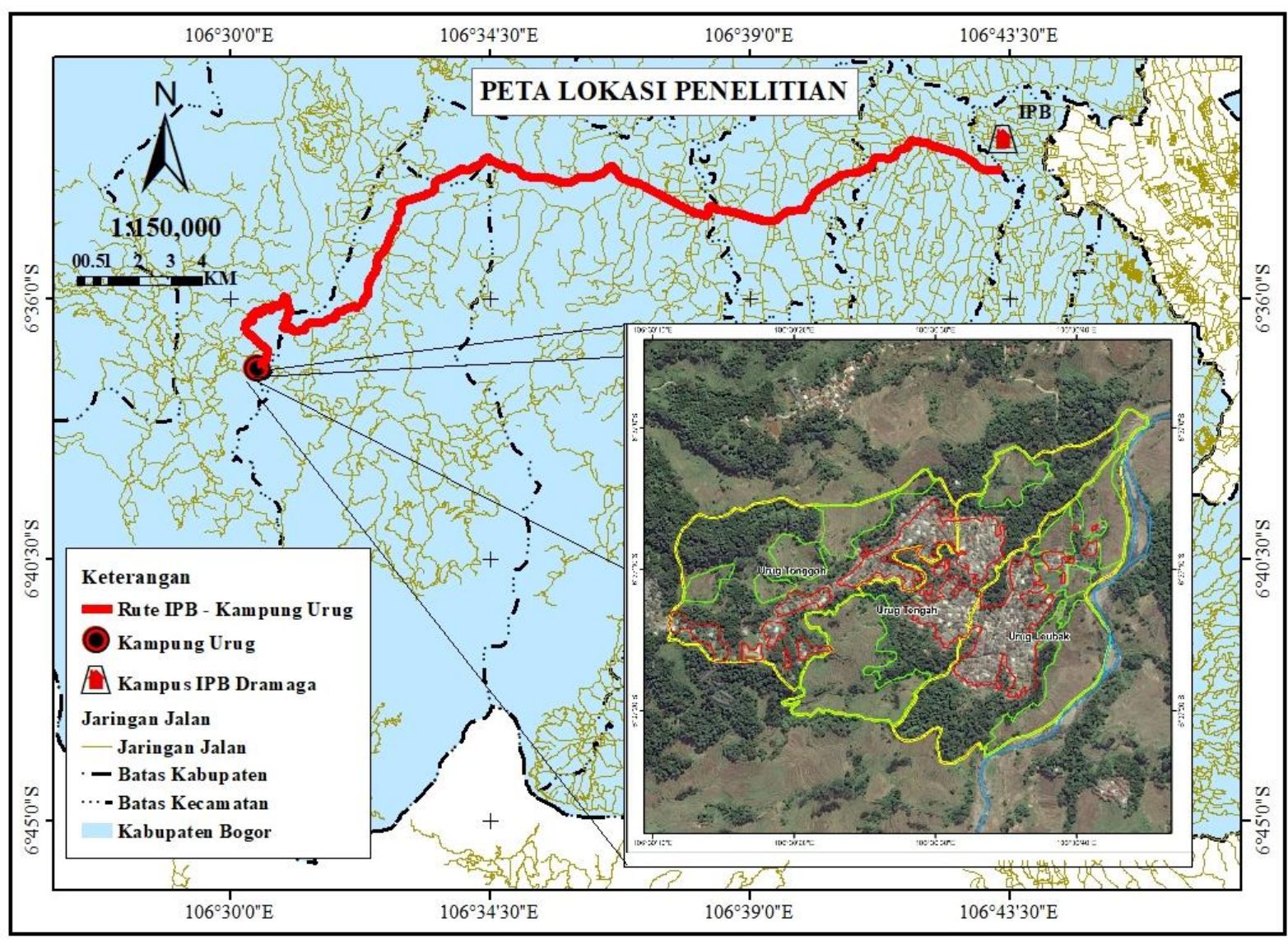

Gambar 1 Peta lokasi penelitian

Analisis data terdiri dari Analisis Deskriptif dan Analisis WOT. Analisis deskriptif kualitatif digunakan untuk memaparkan kondisi sosial budaya masyarakat Kampung Urug serta kondisi potensi ekologi yaitu flora dan fauna (jenis, ciri-ciri morfologi, manfaat, dan habitatnya) sedangkan kondisi bentang alam (sawah terasering dan sungai) dan aksesbilitasnya berdasarkan teori Sugiyono (2005). Sementara itu, analisis data untuk menentukan pengelolaan dengan menggunakan analisis SWOT (strengths, weaknesses, opportunities, dan threats) berdasarkan teori Rangkuti (1997). Analisis ini digunakan dalam menentukan faktor internal dan faktor eksternal ekowisata berbasis masyarakat, kemudian dibuat matriks SWOT dan menentukan kedudukan kuadran dalam pengelolaan ekowisata. Penentuan analisis SWOT diperoleh melalui pengambilan data wawancara yang terdiri dari beberapa pertanyaan utama yaitu :

1. Apakah wisata budaya penting untuk keberlangsungan Kampung Urug?

2. Apakah penting dengan adanya status cagar budaya yang diberikan oleh pemerintah di Kampung Urug?

3. Apakah masyarakat Kampung Urug aktif dalam menjaga dan menjalankan upacara adat?

4. Apakah masyarakat Kampung Urug saling tolong menolong dalam kegiatan upacara adat?
5. Apakah potensi objek daya tarik (bentang alam dan keanekaragaman flora fauna) penting dalam pengembangan ekowisata (pendidikan) di Kampung Urug?

\section{HASIL DAN PEMBAHASAN}

\section{Potensi Ekologi dan Sosial Budaya Masyarakat Kampung Urug}

\section{a. Potensi Ekologis}

Kampung Urug memiliki potensi ekowisata yang cukup besar seperti bentang alam dan keanekargaaman flora dan faunanya. Potensi ini tepatnya berada di wilayah Desa Urug dan akses jalan ke lokasi tersebut harus melalui Kampung Urug. Potensi bentang alam yang dimiliki kampung ini berupa sawah terasering dan sungai seperti yang tersaji pada Gambar 2 .

Gambar 2 (A sawah terasering dan B sungai) menunjukkan potensi objek daya tarik wisata yang dimiliki Desa Urug. Potensi lainnya adalah keanekaragaman flora dan fauna yang bertujuan sebagai edukasi dan objek wisata. Dapat dilihat persentase jumlah jenis keanekaragaman flora yang dijumpai di lokasi penelitian disajikan pada Gambar 3. 
Selain jenis flora, ada juga jenis fauna primata seperti lutung jawa (Trachypithecus auratus), monyet ekor panjang (Macaca fascicularis), dan burung seperti elang jawa (Nisaetus bartelsi), cakakak jawa (Halcyon cyanoventris), dan srigunting (Dicrurus macrocercus), perjumpaan fauna ini berada di persawahan milik masyarakat Desa Urug. Histogram perjumpaan fauna di lokasi penelitian disajikan pada Gambar 4.

Gambar 4 memaparkan bahwa selama tujuh hari dengan lokasi yang berbeda perjumpaan fauna yang paling tinggi adalah monyet ekor panjang dengan total 74 individu. Perjumpaan tersebut berada di lokasi kedua, pada tanggal 11 Januari 2019 di waktu siang hari. Salah satu faktor yang menyebabkan fauna tersebut sering berkelompok adalah adanya penjelajahan menuju lokasi tempat makannya. Lesson et al. (2004) menjelaskan bahwa monyet ekor panjang hidup dalam kelompokkelompok dengan satu kelompok terdiri dari 8 - 40 ekor atau lebih termasuk beberapa betina. Selain monyet ekor panjang, lutung merupakan fauna dengan perjumpaan tertinggi dengan total 48 ekor. Perjumpaan tertinggi terjadi pada tanggal 11 Januari 2019 yang disebabkan cuaca pada lokasi pengamatan cukup mendukung dan ketersediaan pakan memadai berupa pohon mahoni yang memiliki banyak daun muda. Ihsanu et al. (2014) menjelaskan bahwa pakan yang dikonsumsi oleh lutung jawa merupakan pucuk daun yang masih muda dengan cara memetik dengan tangannya.
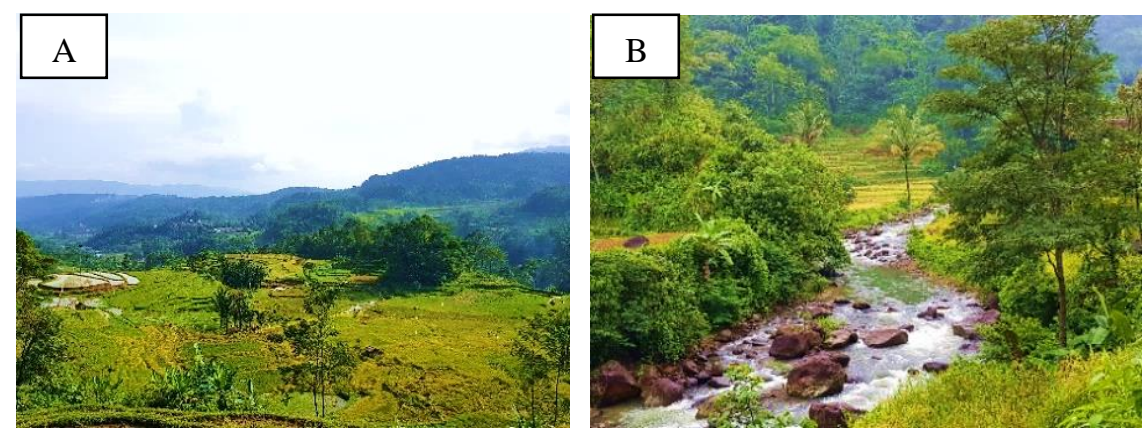

Gambar 2 Pemandangan bentang alam

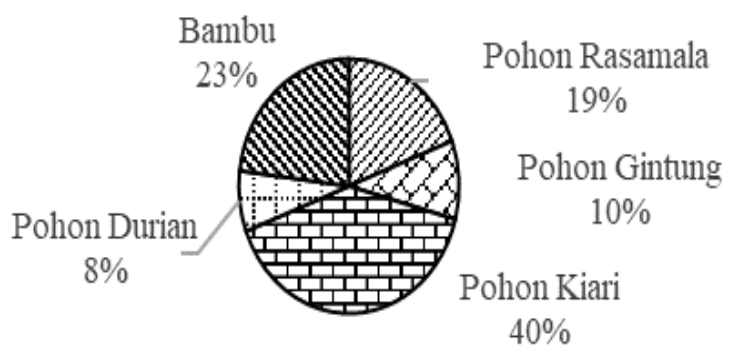

Gambar 3 Persentase jumlah jenis keanekaragaman flora di Kampung Urug

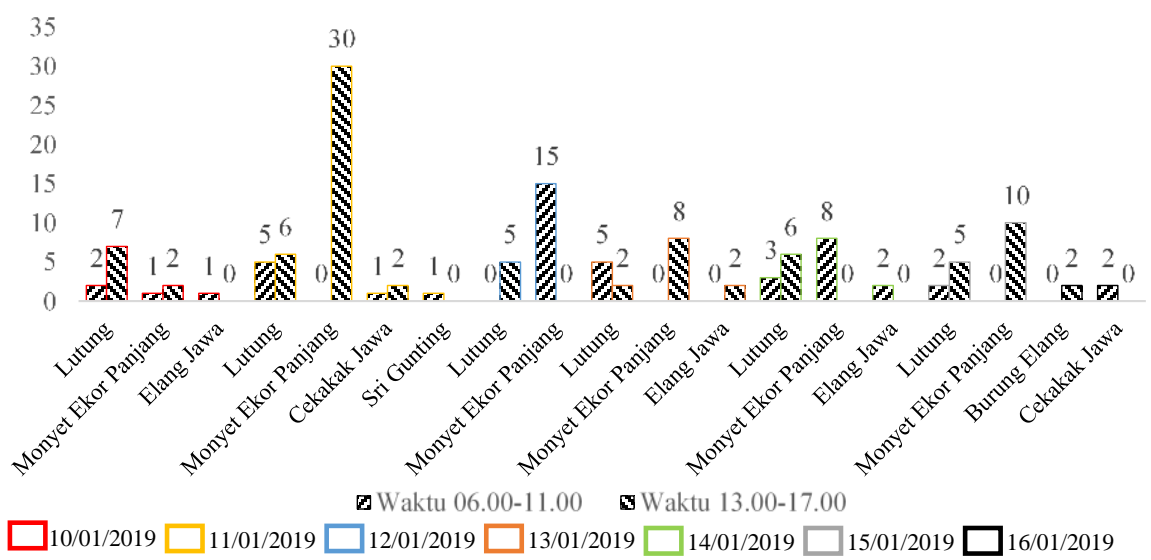

Gambar 4 Histogram perjumpaan fauna 
Jenis burung yang paling banyak dijumpai adalah elang jawa dengan total 7 ekor. Perjumpaan yang paling banyak terjadi pada tanggal 13 dan 16 Januari 2019 di siang hari, dan pada tanggal 14 Januari 2019 di pagi hari. Pada saat siang hari elang jawa mencari mangsa di sekitar sungai dengan terbang menukik seperti dijelaskan oleh Sitorus dan Hernowo (2016) bahwa elang jawa dapat menyambar mangsanya dengan terbang menukik (ambush hunting) apabila pada areal tersebut terdapat areal terbuka, sedangkan pada pagi hari mereka hanya terbang kelilingi lokasi perjumpaan. Jenis burung terbanyak kedua adalah cekakak jawa (5 ekor) dengan perjumpaan tertinggi pada tanggal 11 Januari 2019. Berdasarkan pengamatan, burung ini hanya terbang dan hinggap di dahan pohon, kemudian lanjut terbang untuk mencari makan. Dijelaskan oleh Kamal et al. (2016) bahwa mangsa cekakak jawa merupakan serangga dan hewan-hewan kecil seperti larva kumbang air, dan burung ini mampu memangsa ikan, udang dan katak.

\section{b. Sosial Budaya Masyarakat Kampung Urug}

Masyarakat Kampung Urug dalam kehidupannya tidak terlepas dari kegiatan-kegiatan upacara adat. Upacara ini yaitu upacara sedekah yang selalu dilakukan sebanyak lima kali dalam satu tahun (Ruwahan, Sereun Taun, 1 Muharram, Maulied, dan Sedekah Bumi). Upacara adat tersebut dilaksanakan oleh lembaga adat atau struktur kumpulan kesepuhan ketua adat. Salah satu kegiatan upacara adat yaitu ruwahan (A) dan sereun taun (B) dapat dilihat pada Gambar 5.

Gambar 5 menunjukkan kegiatan upacara adat Ruwahan dilaksanakan pada Bulan Ruwah yang jatuh pada Bulan April untuk mendoakan orang yang meninggal. Pembukaan kegiatan ini dimulai saat terbit matahari dengan membawa minimal satu ekor ayam perkepala keluarga pada pagi hari untuk disembelih secara bersama-sama dan dilanjutkan pada siang hari dimana masyarakat membawa nasi bakul yang berisi ayam tersebut dan berdoa bersama di rumah Ketua Adat. Upacara sedekah Seren Taun merupakan pesta panen yang dilaksanakan sebagai ungkapan rasa syukur masyarakat kepada Yang Maha Esa, kegiatan ini berjalan selama dua hari satu malam yang dimulai saat ba'da subuh dengan penurunan hasil pemanenan, kemudian pada terbit matahari dilanjutkan dengan pemotongan ayam secara bersamaan di satu lokasi. Selanjutnya saat ba'da zuhur sampai asar dengan membawa kue dan nasi bakul untuk berdoa bersama di rumah Ketua Adat, dan dilanjutkan setelah ba'da isya, kumpul bersama dengan menyajikan kue dan menyaksikan pentas seni bersama.

Kampung Urug selain memiliki daya Tarik berupa kegiatan upacara adat juga memiliki situs peninggalan bagunan dan makam leluhur yang masih di jaga sampai sekarang (Bidang Kebudayaan 2009). Gambar 6A merupakan bagunan Gedong Gede atau Rumah Adat yang ditinggalkan oleh ketua adat beserta istrinya yang memiliki enam ruang, salah satu ruangannya digunakan sebagai kegiatan upacara adat (Yogasari 2018). Gambar 6B merupakan makam leluhur pertama yang menjadi ketua adat Kampung Urug.

Dewantara (2013) menjelaskan bahwa ketua adat di kampung ini menjadi kegiatan pertanian sebagai jalan kehidupan masyarakat dan khususnya diwajibkan untuk menanam padi selama satu tahun sekali, karena padi sangat dimuliakan sebagai tanda penghormatan secara syariat. Masyarakat kampung ini juga masih sangat menjaga tradisi dan lingkungan dalam bidang pertanian, seperti masyarakat masih menggunakan irigasi tradisional atau irigasi sederhana, masih menggunakan kerbau dan cangkul untuk membajak tanah, serta air yang digunakan untuk sawah berasal dari sungai dan mata air yang ada dekat di persawahan mereka (Gambar 7A dan 7B).

Kearifan lokal masyarakat Kampung Urug berupa larangan untuk mengambil yang bukan haknya (mengambil atau memetik itu harus meminta izin kepada yang mempunyainya, dengan kata lain jangan mencuri) sama hal diterapkan terhadap hutan larangan dan Gunung Manapa' yang fungsinya sebagai hutan lindung atau sebagai sumber mata air bagi persawahan dan pemukiman masyarakat Urug. Masyarakat kampung harus memiliki sifat yang ramah dan suka memberi atau berbagi, hal ini ditunjukkan saat datangnya pengunjung atau tamu baik itu saat upacara adat diselenggarakan atau di hari-hari bisa, dimana masyarakat selalu menjamu tamu dengan menyapa secara ramah dan sopan serta menghidangkan makan. Hal ini karena mereka belum pernah kekurangan bahan pokok makanan tetutama beras (Dewantara 2013).

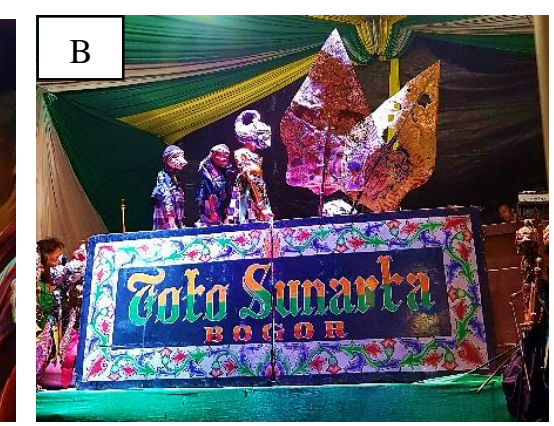

Gambar 5 Kegiatan-kegiatan Upacara Adat 

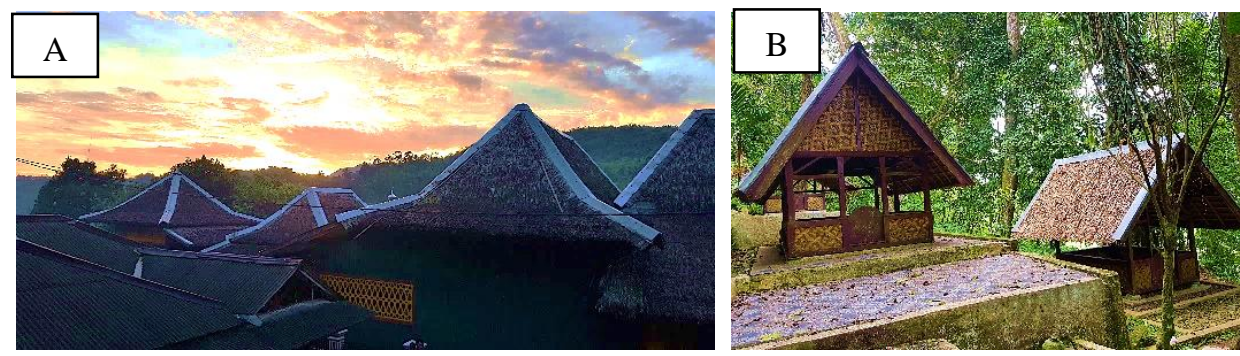

Gambar 6 Situs Bangunan Kampung Urug
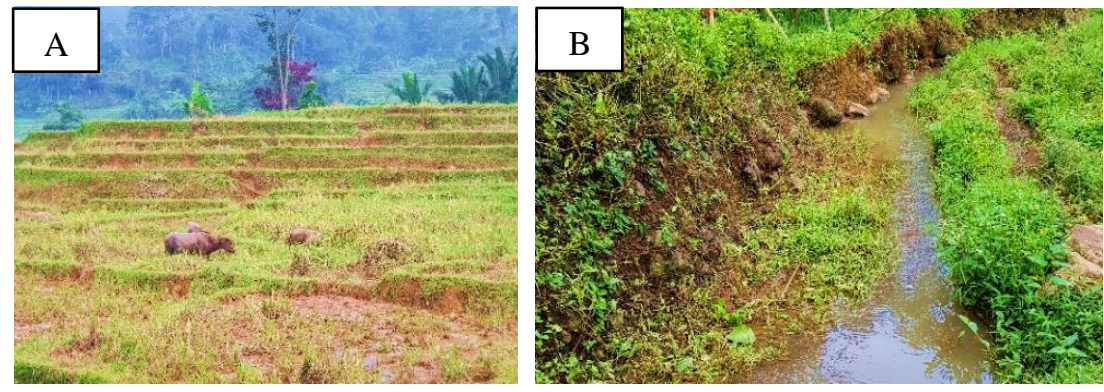

Gambar 7 Irigasi Sederhana dan Bajak Sawah

Kearifan lokal yang dimiliki masyarakat Kampung Urug mampu dikembangkan kearah pengelolaan ekowisata berbasis masyarakat. Salah satu contoh pengelolaannya adalah memberdayakan sifat keramahtamahan masyarakat dalam menawarkan dan menemani tamu ke lokasi potensi ekologis (dalam penelitian ini) serta menyediakan saung yang dilengkapi dengan fasilitas seperti warung kopi tetapi menyatu dengan lingkungan sebagai kegiatan tambahan saat berkunjung dan kegiatan upacara adat. Masyarakat juga mampu menyediakan homestay bagi tamu yang ingin bermalam dan ingin mempelajari kehidupan sosial budaya masyarakat Kampung Urug.

\section{Pengelolaan Ekowisata Berbasis Masyarakat}

Analisis dilakukan dengan memadukan faktorfaktor internal dan eksternal dengan menggunakan matrik SWOT. Ada beberapa sumber yang dapat dijadikan acuan sebagai faktor eksternal. Faktor peluang, pada faktor I yaitu berdasarkan salah satu bantuan pemerintah seperti bantuan dana dalam kegiatan upacara adat dan melindungi kearifan lokal yang dimiliki masyarakat dengan memberikan status sebagai cagar budaya pada tahun 2012. Faktor II berdasarkan profil singkat Kampung Urug yang telah di edit oleh Yogasari (2018), data pengunjung pada tahun 2016 sebesar 195 orang dan tahun 2017 sebesar 370 orang. Faktor II berdasarkan jurnal (Prasetyadi et al. 2005; Dewantara 2013), situs website (https://beritabogor.com/, https://sportourism.id/my-journey-page/, dan http:// disbudpar.bogorkab.go.id/?p=229), dan youtube (News MNCTV, adan MAFR, SMK Insan Madani Sukajaya, dan lainnya). Faktor ancaman, pada faktor II berdasarkan data daftar tamu yang dimiliki ketua adat. Faktor III berdasarkan hasil wawancara dengan RW yang melihat banyaknya pengunjung atau tamu yang datang di Kampung Urug. Martik SWOT menghasilkan delapan alternatif pengelolaan ekowisata berbasis masyarakat yang merupakan perpaduan berdasarkan faktor internal dan eksternal. Pengelolaan ekowisata berbasis masyarakat di Kampung Urug disajikan pada Tabel 1.

Pengelolaan ekowisata berbasis masyarakat di Kampung Urug yang memungkinkan untuk diimplementasikan adalah hasil pertemuan sumbuh $\mathrm{x}$ (faktor internal) dan sumbuh y (faktor eksternal). Berdasarkan selisih jumlah nilai pengaruh unsur internal yaitu antara kekuatan dan kelemahan $(2,17-0,86=1,31)$ dan selisih total nilai pengaruh unsur eksternal yaitu peluang dan ancaman $(2,27-0,49=1,78)$. Sehingga kedudukan pengelolaan ekowisata berbasis masyarakat di Kampung Urug berada pada kuardan I yaitu titik 1,$31 ; 1,78$ (Gambar 8).

Hasil analisis menunjukkan bahwa pengelolaan yang ditemukan dalam ekowisata berbasis masyarakat di Kampung Urug pada Gambar 8 merupakan strategi agresif. Hal ini menunjukkan hasil strategi yang baik dengan mampu memanfaatkan peluang yang ada secara maksimal. Strategi agresif ini masih memerlukan manajemen atau pengelolaan yang tepat untuk memanfaatkan potensi-potensi ekologis dan budaya yang dimiliki agar menjadi kegiatan tambahan (wisata alam dan edukasi) dalam meningkatkan kesejahteraan masyarakat, melestarikan sosial budaya dan lingkungan dengan memperkuat nilai-nilai kearifan lokal yang terkandung di Kampung Urug 
Tabel 1 Matrik SWOT yang dihasilkan dari strategi internal dan strategi eksternal

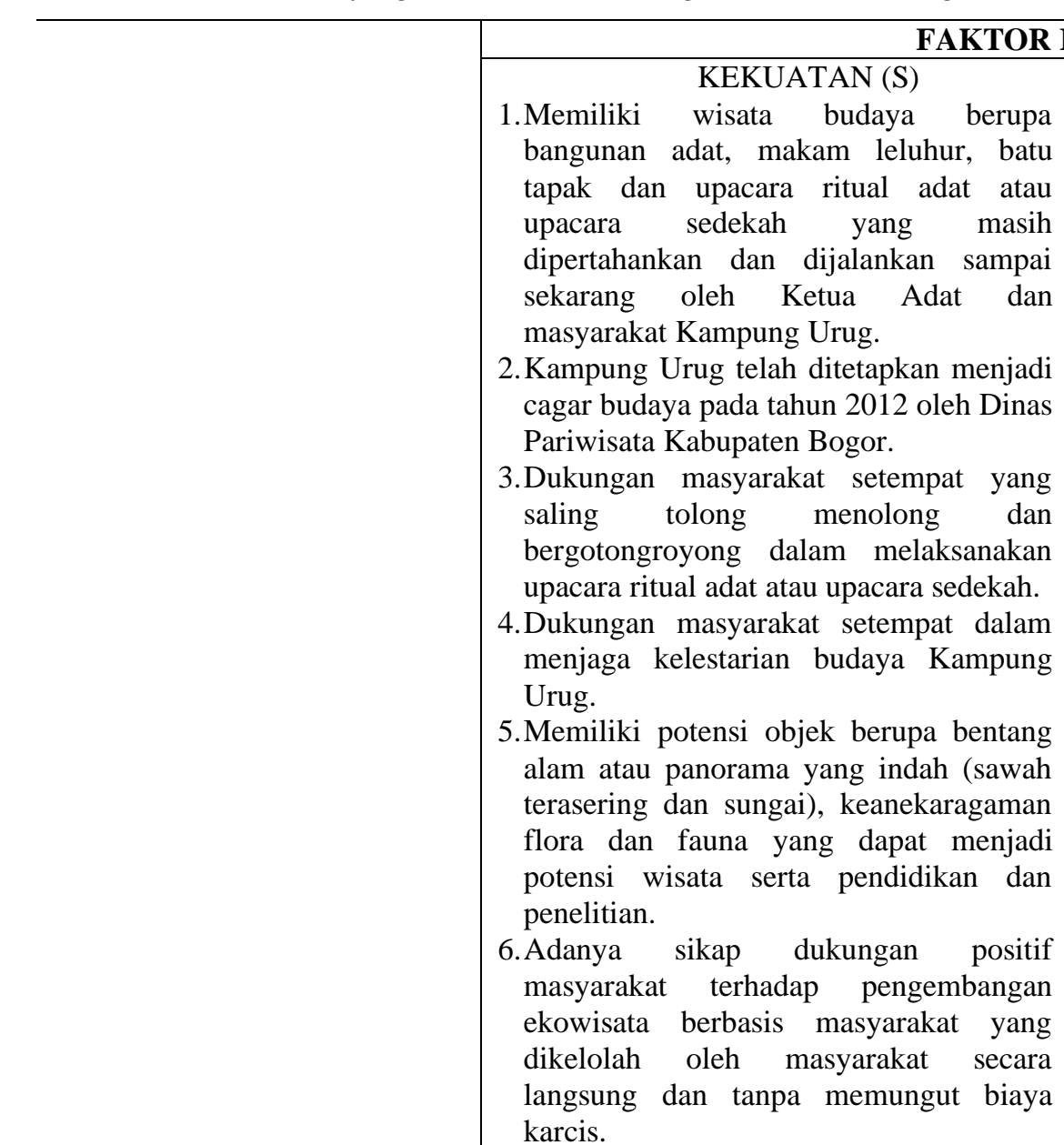

INTERNAL

KELEMAHAN (W)
1. Belum tersedianya secara layak
fasilitas pendukung, seperti standar
penginapan atau homestay bagi
wisatawan dan para pelajar yang
datang.

2.Kurang siapnya masyarakat dalam melayani wisata dan tugas pelajar yang datang, di antaranya kurangnya guide lokal (masyarakat) yang mampu mendampingi wisatawan dan para pelajar di saat ingin berjelajah di lokasi persawahan dan hutan larangan.

3.Tidak adanya aturan yang membatasi pengaruh dari informasi dan teknologi yang mengubah tradisi masyarakat Kampung Urug.

4.Belum adanya identifikasi data jenis flora dan fauna di kawasan Urug.

\section{FAKTOR EKSTERNAL}

\section{PELUANG $(\mathrm{O})$}

1. Adanya dukungan pemerintah desa dan kabupaten untuk mengembangkan ekowisata berbasis masyarakat di Kampung Urug.

2. Adanya peningkatan tren kunjungan wisatawan dan pelajar dari waktu ke waktu, baik dari pulau Jawa maupun luar Jawa terhadap kegiatan ritual adat atau acara sedekah sebagai bentuk wisata budaya berkelanjutan.

3. Informasi tentang Kampung Adat Urug itu sangat mudah didapatkan di internet sehingga secara tidak langsung dapat mempromosikan wisata budayanya.

Strategi (S-O)
1. Memperdayakan masyarakat dalam
melestarikan dan memperkenalkan atau
mempromosikan potensi wisata desa
untuk lebih meningkatkan kunjungan
wisatawan.
2. Memanfaatkan dan meningkatkan
potensi ekologi sebagai objek wisata lain
pada saat jeda waktu di kegiatan upacara
adat Kampung Urug sebagai kegiatan
tambahan bagi pengunjung/tamu yang
datang dengan didampingi oleh guide
lokal yang telah dibekali pemahaman
tentang konsep sapta pesona wisata agar
pengunjung tersebut dapat berkunjung
kembali pada hari biasa

\section{Strategi (W-O) \\ 1.Memanfaatkan dan meningkatkan dukungan pemerintah dengan membangun fasilitas pendukung dan membenah infrastruktur yang masih buruk agar pengunjung yang datang dapat merasakan keamanan dan kenyamanan selama berada di Kampung Urug. \\ 2.Meningkatkan pemahaman} masyarakat Kampung Urug tentang ekowisata berbasis masyarakat agar tidak ada kesalahpahaman dan pertentangan dalam pengembangan ekowisata nantinya.

3.Memberdayakan masyarakat Kampung Urug sebagai guide lokal dengan memberikan bekal pemahaman tentang konsep sapta pesona wisata agar wisatawan yang datang dapat berkunjung kembali di Kampung Urug.

4.Memanfaatkankan dukungan pemerintah untuk memperkenalkan 
Tabel 1 Matrik SWOT yang dihasilkan dari strategi internal dan strategi eksternal (Lanjutan)

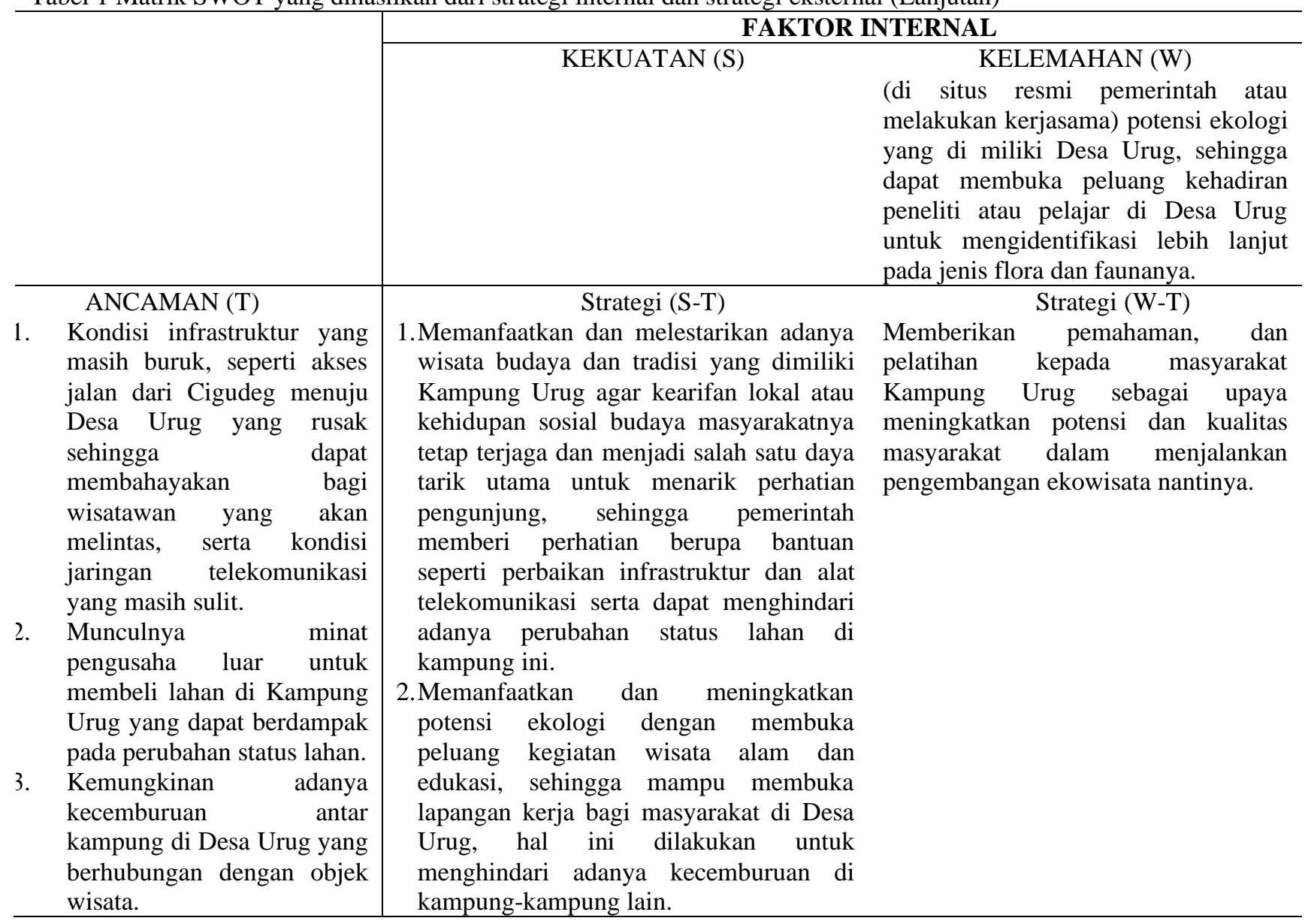

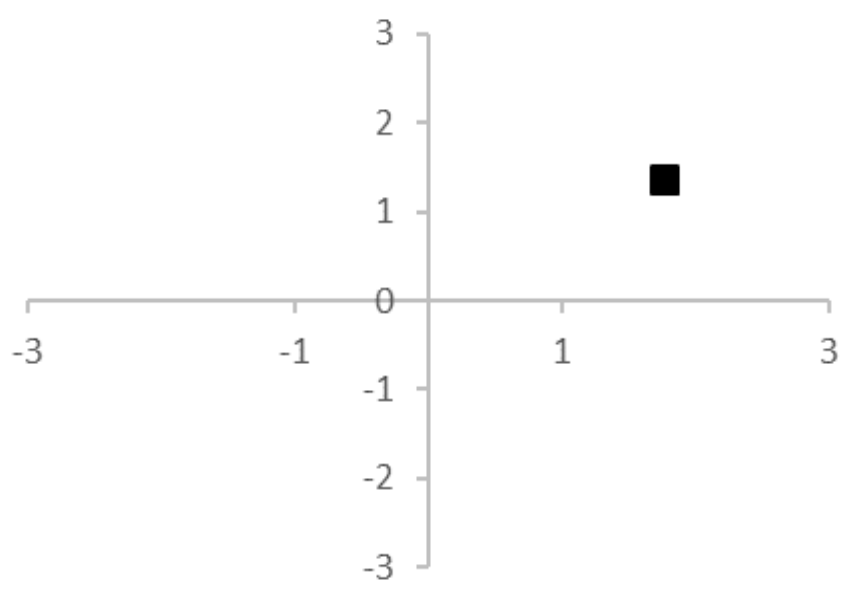

Gambar 8 Kedudukan strategi pengembangan ekowisata berbasis masyarakat di Kampung Urug berdasarkan analisis SWOT

\section{SIMPULAN}

Berdasarkan hasil penelitian maka adapun simpulan dari penelitian ini, yaitu Kampung Urug memiliki potensi ekologi yaitu jenis flora yang dimanfaatkan oleh masyarakat kampung ini berupa pohon rasamala, pohon gintung, pohon durian, pohon kirai, dan bambu, dan jenis fauna yang ditemukan berupa jenis lutung, monyet ekor panjang, elang jawa, cekakak jawa, dan srigunting. Bentang alam yang dimiliki desa ini merupakan sawah terasering dan sungai. Potensi-potensi ini bisa menjadi suatu kegiatan tambahan seperti wisata alam dan edukasi serta meningkatkan kualitas hidup masyarakat kampung 
ini melalui peluang pekerjaan seperti guide lokal, pedangan (warung campuran, warung makan, dan warung kopi), dan ojek.

Strategi yang dihasilkan dalam penelitian ini merupakan strategi agresif menunjukkan hasil strategi yang baik dengan mampu memanfaatkan peluang yang ada secara maksimal.

\section{DAFTAR PUSTAKA}

Alikodra HS. 2000. Pengelolaan Satwaliar Jilid I. Bogor: Yayasan Penerbit Fakultas Kehutanan.

Bidang Kebudayaan. 2009. Data Kampung Adat Di Jawa Barat.

Dewantara A. 2013. Peran elit masyarakat: Studi kebertahanan adat istiadat di Kampung Adat Urug Bogor. Al-Turas. 19 (1): 89-117.

Ihsanu IA, Setiawan A, Rustiati EL. 2014. Studi perilaku makan dan analisis vegetasi pakan lutung jawa (Trachypitecus auratus) di Taman Nasional Gunung Cermai. Jurnal Sylva Lestari. 1(1):17-22

John RB, Vijayan PK. 2018. Positive and negative impacts on ecotourism: A case study of Ponmudi in Thiruvananthapuram District, Kerala. International Journal of Research in Humanities, Arts and Literature. 6(5): 405-410.

Kamal S, Agustina E, Rahmi Z. 2016. Spesies burung pada beberapa tipe habitat di Kecamatan Lhoknga Kabupaten Aceh Besar. Jurnal Biotik. 4(1): 15 - 32.
Lesson C, Kyes RC, Iskandar E. 2004. Estimating population density of longtailed macaques (Macaca fascicularis) on Tinjil Island, Indonesia, using the line transect sampling method. Jurnal Primatologi Indonesia. 4(1): 7 -14.

Prasetyadi BS, Apidianto, Nugroho W. 2005. Kearifan Orang Sunda Di Kampung Urug yang Terpencil Tinjauan Psikologi Sosial dan Arsitektur. Proceeding, Seminar Nasional PESAT. Jakarta: Universitas Gunadarma.

Rangkuti F. 1997. Analisis SWOT Teknik Membedah Kasus Bisnis: Reorientasi Konsep Perencanaan Strategi untuk Menghadapi Abad 21. Jakarta: Gramedia Pustaka Utama.

Sekartjakrarini S. 2004. Ekowisata: Batas dan Pengertian. Dalam Seri Ekowisata. Jakarta: IdeA.

Sitorus DN, Hernowo J. 2016. Habitat dan perilaku elang jawa (Nisaetus bartelsi) di SPTN 1 Tegaldlimo Taman Nasional Alas Purwo, Jawa Timur. Media Konservasi. 21(3): 278- 285.

Sugiyono. 2005. Memahami Penelitian Kualitatif. Bandung: Alfabeta

Widada. 2008. Mendukung Pengelolaan Taman Nasional yang Efektif Melalui Pengembangan Masyarakat Sadar Konservasi yang Sejahtera. Jakarta: Ditjen PHKA-JICA.

WWF Indonesia. 2009. Prinsip dan Kriteria Ekowisata Berbasis Masyarakat. Jakarta: Departemen Kebudayaan dan Pariwisata dan WWF-Indonesia.

Yogasari V. 2018. Profil Singkat Kampung Adat Urug, Kesepuhan Urug Lebak [tidak dipublikasikan]. 